\title{
Experimental Liver Transplantation
}

\author{
Mirela Patricia Sîrbu Boeți, Sadiq Shoaib, \\ Alaa Elshorbagy, Cătălin Iulian Efrimescu and Irinel Popescu \\ Fundeni Clinical Institute, Department of General Surgery and Liver Transplantation
}

Romania

\section{Introduction}

The development and implementation of different surgical techniques and immunosuppressive regimens in liver transplantation have been based upon animal experimental studies. The first experimental attempt for liver transplantation was reported on dogs, in 1955, by Welch (Welch, 1955), who described the insertion of a heterotopic auxiliary liver, engrafted in either the pelvis or right paravertebral gutter. The portal vein was anastomosed to the inferior vena cava and the hepatic artery to the aorta or iliac artery, and no immunosuppression was used. The first experimental liver replacement with orthotopic liver transplantation (OLT) was reported by Cannon at the University of California at Los Angeles in 1956, but none of those dogs survived. (Cannon, 1956)

Surgical techniques for experimental orthotopic liver transplantation on pigs were started by Garnier and colleagues in 1965 (Garnier et al., 1965), and continued by Cordier and colleagues in 1966 (Cordier et al., 1966), Mieny and colleagues in 1967 (Mieny et al., 1967), Calne and colleagues in 1968 (Calne et al., 1968). Surgical techniques and vascular bypass methods used on pigs were transposed from dogs. Methods of passive venous bypass used by Moore (external portal and systemic bypass) (Moore et al., 1959) and Starzl (external sideto-side portacaval bypass) (Kaupp \& Starzl 1960) on dog models facilitated the development and use by Calne of portal-jugular and portal-caval-jugular passive venous bypass methods and later the active venous bypass method on pigs (Calne et al., 1968).

Pig orthotopic liver transplantation models offer some advantages over the dog models: (1) pigs are considered the most realistic choice due to the low cost, availability, and ethical reasons; (2) there is no outflow phenomenon because, different from dogs, pigs have no muscular sphincters at the confluence of suprahepatic inferior cava vein which tangle the blood flow at this level; (3) pig liver orthotopically transplanted into another animal remains fully functional even for periods of months without immunosuppressive therapy; (4) pig models offer a much closer resemblance with the human liver transplantation than dog models, because the pig liver is a firm and coherent organ, composed of eight segments (Filipponi et al., 1995) homologous to those of the human liver.

Although pig liver transplantation models are favored, both anesthesia team and surgical team are challenged by anatomical and physiological differences between human and pig. The experimental studies must be in conformity with the International Guidelines of Biomedical Research Involving Animals. 
In the present chapter we focus upon anesthesia and surgical procedures used by different authors for the orthotopic liver transplantation on swine model.

\section{Preoperative preparation}

The importance of conducting a proper anesthesia begins with the preoperative preparation in order to avoid the occurrence of potentially lethal malignant hyperthermia and porcine stress syndrome. Thus a very gentle handling with a minimum distress for pigs must be acknowledged. Before surgical interventions, the animals should be left to adapt to the environment for 24-48 h. Some authors recommend to have the animals delivered at least 2 to 3 weeks before the experiments to get them acclimated to the personal conditions, location, and food. (Kaiser et al., 2006) The operations should be performed after a 12-24 $\mathrm{h}$ starvation period. During this time only ad libitum oral water intake is admitted. Brute force should be avoided. The immobilization of the pig should be conducted only by experienced staff otherwise it is stressful for both the animal and researcher.

\section{Anesthesia}

An anesthesia protocol is proposed: i.m. pre-anesthesia using Atropin $0.015 \mathrm{mg} / \mathrm{kgc}$, Midazolam $2 \mathrm{mg} / \mathrm{kgc}$, Ketamine $10 \mathrm{mg} / \mathrm{kgc}$, i.v. (marginal ear veins) induction with Propofol $3 \mathrm{mg} / \mathrm{kgc}$, gas maintained anesthesia with Halotane $3 \%-4.51 / \mathrm{min}$ and orotracheal intubation. (Sirbu Boeti et al., 2008) Before intubation, $100 \% \mathrm{O}_{2}$ is delivered via an inhalation mask to obtain a very good oxygenation of the animal. The orotracheal intubation is quite cumbersome but can be surpassed by positioning the pig in ventral decubitus and using a laryngoscope with long blade and a mandrel. (Kaiser et al., 2006) In difficult situations, larynx and trachea are manipulated from the outside to permit passage of the $6 \mathrm{Fr}$ endotracheal tube. It is important for intubation to have the swallowing reflex completely abolished. The endotracheal tube is blocked by inflating the balloon with air and fixed with a bandage. The auscultation of the chest must confirm the proper positioning of the tube. The anesthesia machine is adjusted for a tidal volume of $500 \mathrm{ml}$ at a ventilation rate of 18-20 per minute. A venous line should be mounted on each ear for drug administration. A drainage tube should be passed via mouth into pig's stomach to deflate it during the operation. The anesthesia depth can be assessed by mandible relaxation, inferior-medial eye balls deviation, and corneal reflex. During the entire intervention for both donor and recipient, SpO2, heart rhythm and respiratory frequency should be monitored. Body temperature is another important parameter to check using an intrarectal probe. However, the clinical observation of the swine remains a major part of the continuous monitoring of the pig. (Kaiser et al., 2006)

Pigs are extremely sensible to medication administered during preanesthesia or anesthesia induction, being prone to developing epidermal allergic phenomenon with generalized skin rush, which may be relieved by corticoid administration. Although rare, an example of drug side effect is represented by the rapidly progressive liver decompensation with intraoperative death due to Halothane inhalation. Other inhaled anesthetics such as Isoflurane or Sevoflurane are better alternatives.

There are two main anatomical differences between human and pig with great impact on the liver transplantation technique: (1) intrahepatic parenchymal trajectory of inferior vena 
cava (Filipponi et al., 1995; Fondevila et al., 2010) which makes the dissection of this vein off the hepatic parenchyma impossible in pigs; (2) the existence of a very short segment of suprahepatic inferior vena cava, intimately attached to the diaphragm, which leads to difficulty in hepatic vascular reconstruction. (Sirbu Boeti et al., 2008)

Donor and recipient pigs can be operated on by the same team of surgeons. All the surgeons of the team should posses basic skills in microsurgical techniques.

\section{Donor operation}

The donor operation is generally performed using only an intravenous catheter placed at the start of anesthesia.

For liver harvesting, the abdomen of the donor pig is entered via a midline incision, avoiding the urethra. The liver is exposed after appropriate bilateral costal retraction, careful packing, and caudal retraction of the bowel. The liver is mobilized by dividing the falciform ligament, triangular ligament, and gastrohepatic ligament. The hepatic pedicle is exposed by moving away the small bowel using caudal and left traction of the bowel. The pedicle's elements are dissected and hepatic artery, portal vein, and common bile duct are encircled and isolated with a loop. Pedicle's elements must be dissected and divided as close as possible to the duodenum, obtaining an increased length for anastomosis. Inferior vena cava is dissected above and below the liver in order to permit its harvesting together with the whole liver. The skeletonization of the common bile duct should be avoided. The gallbladder is incised and drained if a biliary reconstruction with the cholecyst is planned. If not, an antegrade or retrograde cholecystectomy is performed. Aorta is exposed at the level of celiac trunk and iliac bifurcation on loops. The subject should receive $100 \mathrm{UI} / \mathrm{Kgc}$ of Heparine before splenic vein and aorta cannulation. The previously encircled terminal aorta is cannulated under the renal arteries for blood collection. The collected blood can be used during liver engraftment as needed. After $500 \mathrm{ml}$ blood collection from the aorta, the preservative solution (e.g. lactated Ringer's solution) cooled at $4^{\circ} \mathrm{C}$ is infused through portal cannula while the supraceliac and terminal aorta together with supra and infrahepatic vena cava are cross-clamped. Outflow of the infused solution is provided by inferior infrahepatic inferior vena cava through a slit made by cutting its wall. The liver effluent can also be allowed to drain into the thoracic cavity by cutting the diaphragm and suprahepatic inferior vena cava. Core cooling is supplemented by topical sterile ice.

The liver can be perfused not only by the portal vein alone (single) but also by both the hepatic artery and portal vein (dual). (Foley et al. 2003) Some authors found that aortic flushing shortened the operation times and proposed it for routine liver procurement even from hemodynamically stable donors. (Filipponi et al., 1996)

After core cooling, all the vascular attachments are divided. Hepatic artery is harvested with celiac trunk and a segment of abdominal aorta, after all branches of celiac trunk are divided. Portal vein should be transected near duodenum after one liter of cold preservation fluid has passed through the liver. Cranially inferior vena cava must be divided highly into the thorax maintaining a little rim of diaphragm around it. Caudally inferior cava vein is transected at the level of the right renal branch. When all vascular and peritoneal connections are transected, the liver is extracted from donor abdominal cavity. After liver harvesting the donor pig should be euthanasiated. 
On the back table the fresh harvested liver is rinsed via portal infusion with $3 \mathrm{~L}$, for each $\mathrm{kg}$ of liver mass, of cooled $\left(4^{\circ} \mathrm{C}\right)$ preservation solution (e.g. normal saline, lactated Ringer's solution, Celsior solution (CS), an extracellular preservation solution, with Viaspan (University of Wisconsin solution, UW) (Audet et al., 2001), Collins C2 solution). UW solution can be supplemented with epidermal growth factor, insulin-like growth factor-1, nerve growth factor-beta, bactenecin, and substance $P$ to create TF-supplemented (TFS) UW. If TFS UW is used instead of UW, hepatic function is better preserved when orthotopic liver transplantation is performed after $18 \mathrm{hr}$ of static cold storage at $4^{\circ} \mathrm{C}$. (Ambiru et al., 2004) OLT without cold perfusion of the donor liver is also feasible and prolonged survival of animals is possible, but the function of these organs is markedly reduced compared to the cold perfused organs. (Barbier et al., 1986) The liver is kept in the cold solution until implantation in the recipient. The donor liver is carefully prepared in order to secure any potential vascular bleeding points and adequately clean the vascular structures to facilitate anastomotic procedures. Lymphatic tissue from the pedicle is carefully removed.

\section{Recipient operation}

The operation on recipient can be performed with or without veno-venous bypass. (Falcini et al., 1990) The bypass can be active or passive.

The pig poorly tolerates simultaneous clamping of the liver pedicle and inferior vena cava. Pigs are sensitive to the congestion of portal vein system. Obvious intestinal mucosa injury are noticed $45 \mathrm{~min}$ after blockage. Another issue is the retention of blood flow in portal vein system. Having short limbs and strong gastrointestinal tract, pigs have a high blood flow in portal vein and severe congestion in portal vein system certainly leads to whole body's hemodynamic disturbances. The transplant without veno-venous bypass leads to severe hemodynamic disturbances. Hypotension occurs after more than 30 minutes and leads to immediate or late irreversible shock. (Battersby et al., 1974) Temporary clamping of the supracoeliac aorta is performed by some authors to stabilize the hemodynamic conditions during the anhepatic phase without venous bypass. If the anhepatic phase without veno-venous bypass lasts less than $30 \mathrm{~min}$, temporary aortic occlusion may not be mandatory. If the anhepatic time is less than $20 \mathrm{~min}$, postreperfusion hypotension with reflex tachycardia is transient and responsive to i.v. fluid perfusion. (Fondevila et al., 2010)

In case of a $Y$ type veno-venous bypass afferent limb is placed into the jugular vein and two efferent limbs are placed into splenic vein and inferior cava vein. Before starting vascular cannulation, $100 \mathrm{UI} / \mathrm{Kgc}$ dose of Heparine should be administered to the recipient. The vascular cannula is filed with a saline-Heparine solution to remove air bubbles. Venovenous bypass is associated with an increased risk of bleeding, disorders of coagulation, air embolism, and venous thromboembolism. (Oike et al., 2001)

The anesthetized animal is placed on its back, the skin is prepared and the draping is made so as to allow the left cervical access to jugular veins and the midline abdominal incision. The operation begins with the dissection and cannulation of the left external jugular vein. If the external jugular vein is too thin to be cannulated, the ipsilateral internal jugular vein can be used instead. The cannula is placed through a longitudinal venotomy in the jugular vein. The cranial end of the vein is ligated and the outside end of 
the cannula is clamped until the introduction of the efferent limbs of the veno-venous bypass. The placement of the cannula should be done with caution to avoid all the air bubbles. After securing the afferent limb of the bypass, the abdomen of the recipient is opened via a vertical xifo-infraumbilical incision. The steps of abdominal operation are: establishment of the veno-venous bypass, hepatectomy, and engrafting of the donor liver. Prior to the mounting of the efferent limbs of veno-venous bypass, the mobilization of the liver and dissection of the elements of liver pedicle (Figure 1,2), splenic vein (Figure 3), and inferior cava vein should be done. The technique of hepatectomy is similar to that performed on donor with special attention at the dissection of all the vessels and the bile duct near the liver in order to obtain maximal lengths of these structures needed for tension-free anastomoses.

The first efferent cannula is inserted into splenic vein via a longitudinal venotomy. The cannula is advanced maximum $3 \mathrm{~cm}$ toward portal vein in order to avoid the obstruction of the venous branches, especially the superior mesenteric vein. The cannula is secured in position with a simple suture. The other segment of splenic vein is ligatured at the level of the splenic hilum. The second efferent limb of the bypass is inserted into infrahepatic inferior cava vein after its complete transversal section. The cannula is advanced caudally in the inferior vena cava maximum $2 \mathrm{~cm}$ toward but not obstructing the right renal vein opening. The cranial stump of inferior cava vein is clamped. The cannula is fixed similar to the first one. The active circulation can be maintained by Medtronic 550 Bio-Console Pump Speed equipped with a Medtronic Bio-Pump ${ }^{\circledR P l u s}$ centrifugal blood pump with flow capacity of $30 \mathrm{ml} / \mathrm{kg} / \mathrm{min}$. (Sirbu Boeti et al, 2008) When using vascular bypass great caution must be paid to the catheters' preparation and insertion in order to avoid air embolism and also blood clothing. For these, it is recommended to maintain all the catheters clamped until all of the veins are catheterized and their removal should be done selectively starting with portal vein and continuing with inferior vena cava, and ending with jugular vein, immediately after completing all the three venous anastomoses. It is also necessary to check all the tubes before connection by forced injection of Heparine-saline solution for the identification of the possible holes that can lead to air embolism, and maintain them filled with the same solution. In our previous study the active portal-caval jugular bypass proved to be better than the passive portal-jugular bypass. (Sirbu Boeti et al. 2008) Moreover other authors reported a low number of complications by using the active versus pasive bypass (e.g. pelvic congestion, that is the main cause for deep venous thrombosis and pulmonary emboli). (Filipponi et al., 1989; Filipponi et al., 1996, Filliponi et al., 1998)

Maintaining a good stability in pulmonary hemodynamics during anhepatic period, together with a low rate of complications if properly used, the active portal-caval jugular bypass seems to be the standard for OLT in pigs.

Regarding the engrafting technique, the most difficult problem in pigs is related to suprahepatic inferior caval vein anastomosis. The problem is raised by the fact that there is a very short segment of suprahepatic inferior caval vein. This anatomic feature determines to position the clamp on the inferior vena cava with the inclusion of a portion of the diaphragm. After transaction of inferior vena cava nearby the diaphragm, the opening of remaining vena cava to be anastomosed is kept enlarged due to the intimate connections with the diaphragmatic fibers. To overcome the incongruence between the cava vein edges two solutions can be applied. 


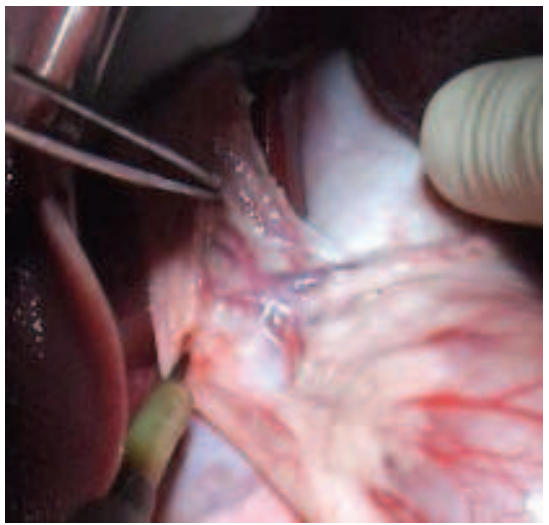

Fig. 1. Dissection of the hepatic hilum. Left, median, and right hepatic artery are identified

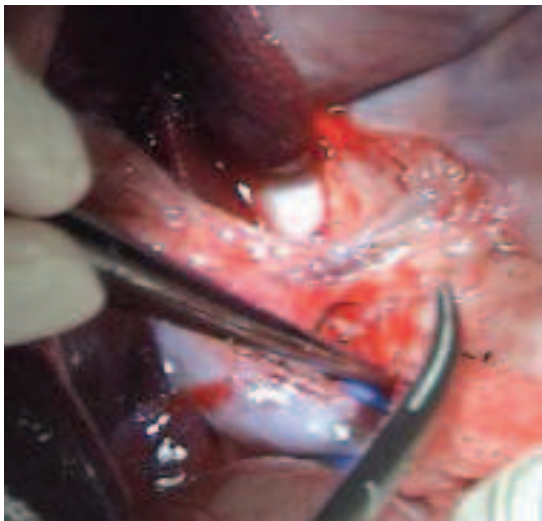

Fig. 2. Porta vein is dissected and encircled

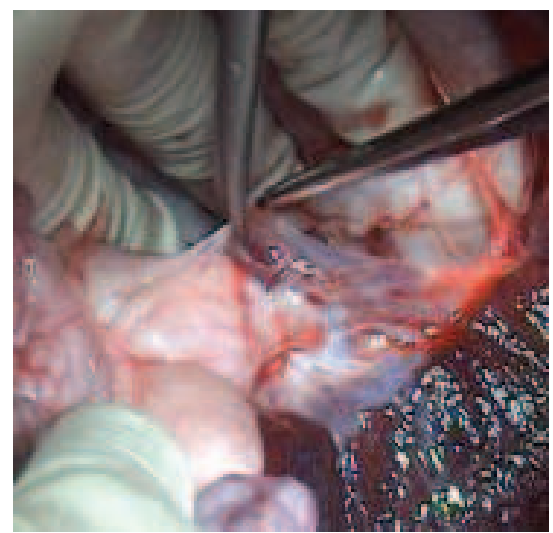

Fig. 3. The splenic vein is dissected near the splenic hilum for the introduction of one of the efferent limbs of veno-venous $Y$ bypass 
In most situations an adequate calibration of the donor inferior caval vein edge is needed. The most appropriate is the enlargement of the stump by suturing a $\mathrm{V}$ venous patch obtained by harvesting the liver together with a long segment of intrathoracic inferior cava vein.

The possibility to perform an end-to-end anastomosis between donor and recipient caval vein without plasty exists but it is best accomplished entering the thoracic cavity via a phrenectomy around the inferior caval vein. For this approach longer segment of the donor inferior caval vein is also needed and must be tailored by transecting it as high as possible into thorax. However this second method is cumbersome due to the difficulty of the diaphragm reconstruction and impossibility of obtaining a tight sealing of the thoracic cavity.

Immediately after declamping of the three cannula (inserted into splenic, inferior vena cava and jugular vein) and the activation of veno-venous bypass, the clamping and transection of the biliary common duct (Figure 4), hepatic artery, portal vein (Figure 5), and suprahepatic inferior vena cava (Figure 6) are done and the liver is removed. These anatomic structures should be transected near the donor's liver. After liver removal, donor's suprahepatic inferior vena cava is prepared for anastomosis by trimming the remnant liver parenchyma (Figure 7).

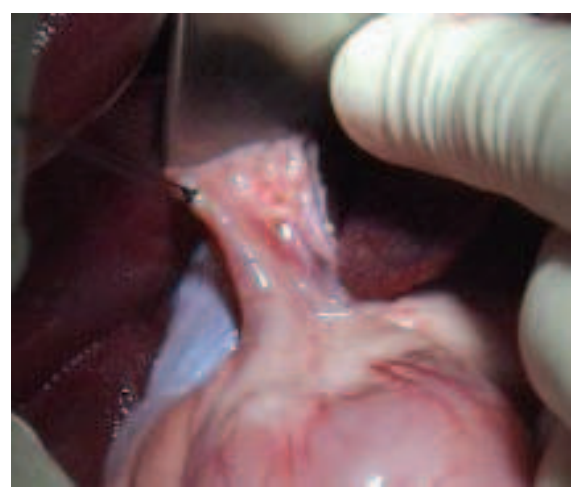

Fig. 4. Recipient's choledoch is identified and prepared to be cut between ligatures near the liver. The skeletization of the choledoch in hepatic hilum is avoided

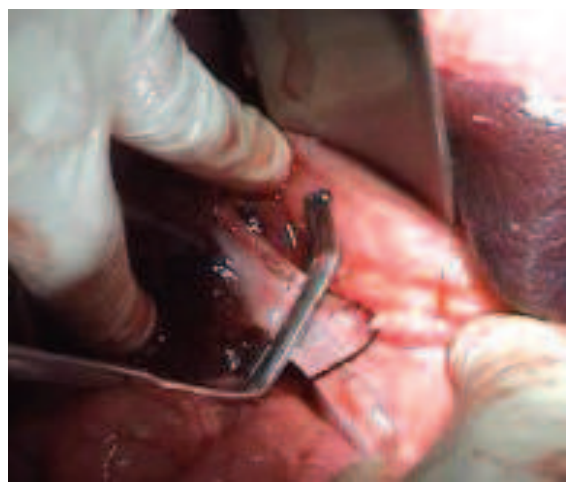

Fig. 5. Recipient's portal vein is clamped near the liver 


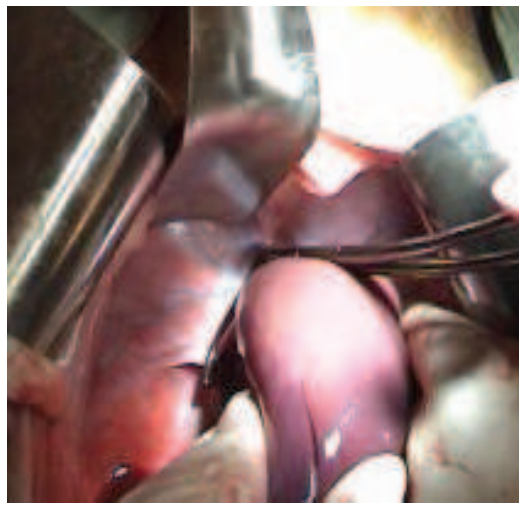

Fig. 6. Recipient's suprahepatic inferior vena cava is clamped by including the adjacent diaphragm into the clamp

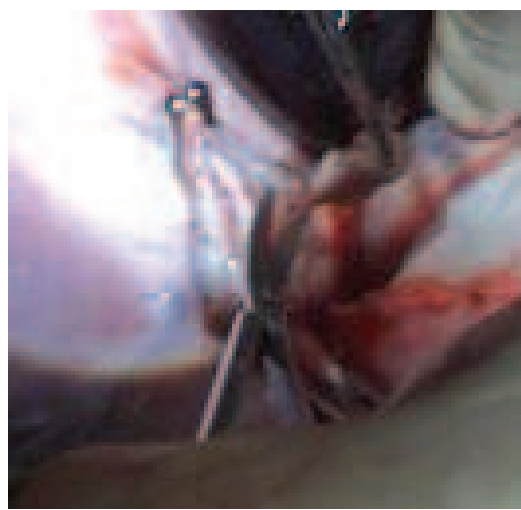

Fig. 7. Donor's suprahepatic inferior vena cava is prepared for anastomosis by removal of remnant liver parenchyma

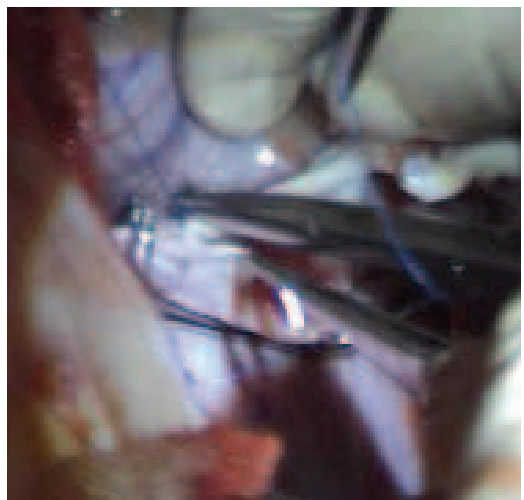

Fig. 8. Suprahepatic inferior vena cava is reconstructed in end-to-end fashion by starting the continuous suture on the left side and finishing it on the right side 
Although models without the usage of bypass were described by some authors (Oike et al., 2001), our previous results were better when the bypass was used. (Sirbu Boeti et al., 2008)

After its back table preparation, the donor liver is properly placed and oriented into the right subphrenic space. The anastomoses are performed in the following order: suprahepatic inferior cava vein, portal vein, infrahepatic vena cava, arterial anastomosis, and biliary anastomosis remnant.

The end-to-end anastomoses of inferior caval vein should be made using continuous suture of 5-0 monofilament polypropylene (Prolene ${ }^{\circledR}$, Ethicon, Inc.), starting with the left wall and finishing with the right wall (Figure 8).

While completing the suprahepatic caval anastomosis, the liver is perfused with warm lactated Ringer's solution to remove the air bubbles (Figure 9).

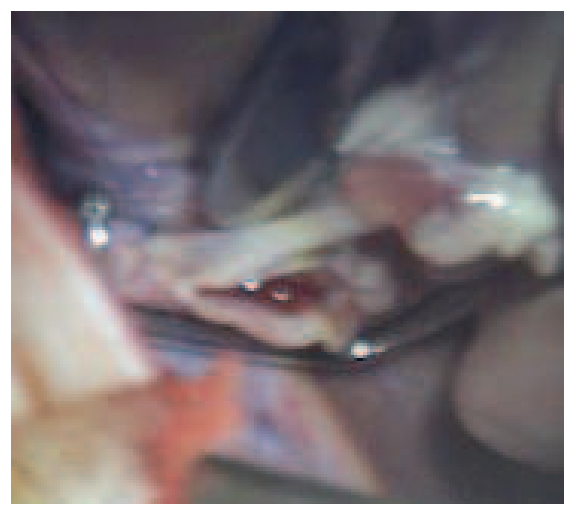

Fig. 9. The anastomosis of the suprahepatic inferior cava vein is continued on the right wall while liver is perfused with warm lactated Ringer's solution

Portal vein reconstruction is started with a continuous 5-0 monofilament polypropylene on the posterior wall (Figure 10) and is continued with the anterior wall. Before completing the anterior wall of the portal vein anastomosis, $500 \mathrm{ml}$ of lactated Ringer's solution at room temperature are flushed into the liver, and after completing it portal vein clamp is removed and splenic cannula is cross-clamped. Both lactated Ringer's solution and about $250 \mathrm{ml}$ of blood are let to flow out of the liver through the infrahepatic inferior vena cava stump, in order to wash-out the oxide radicals and the high potassium-containing preservation solution, and decrease the risk of hypothermic stress. It is important to tie the last suture of portal vein anastomosis leaving a growth factor of about half of the diameter of the anastomosis. Thus stenosis of portal vein is avoided on long term animal survivals. Before performing the infrahepatic inferior vena cava anastomosis, the tightness of suprahepatic vena cava (Figure 11) and portal anastomosis is verified (Figure 12).

After the suprahepatic inferior cava vein and portal vein are declamped, reperfusion of the liver is re-established (Figure 13). The infrahepatic inferior caval vein of the donor liver is clamped proximal the right renal vein and the vena cava cannula is withdrawn in order to perform the anastomosis with the inferior vena cava (Figure 14, 15) of the recipient. The anastomosis is performed with continuous suture of 5-0 monofilament polypropylene. 


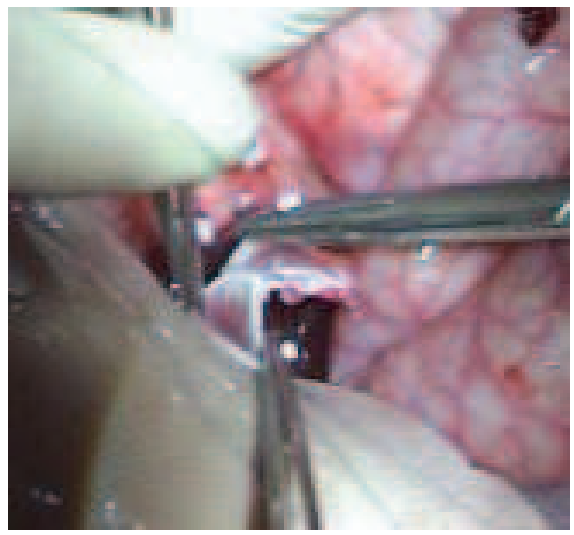

Fig. 10. Reconstruction of the portal vein starting with a continuous suture of the posterior wall

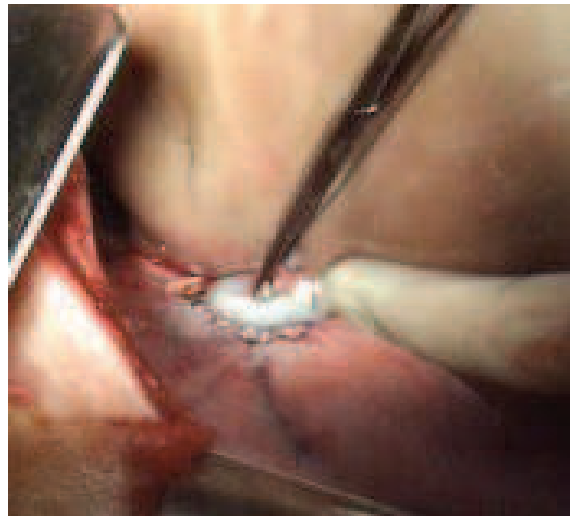

Fig. 11. Check-up of suprahepatic inferior caval vein anastomosis

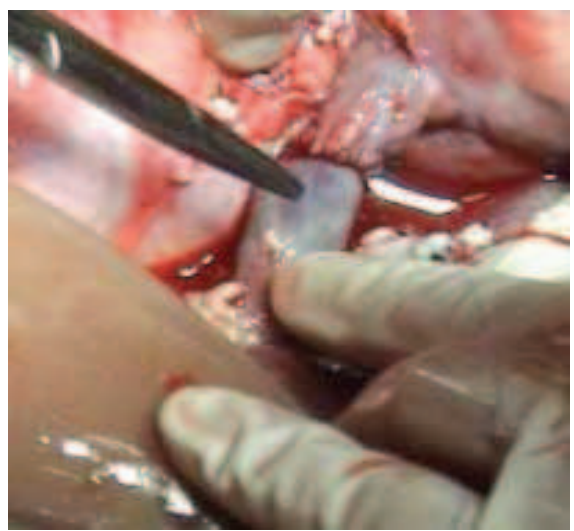

Fig. 12. Check-up of portal vein anastomosis 


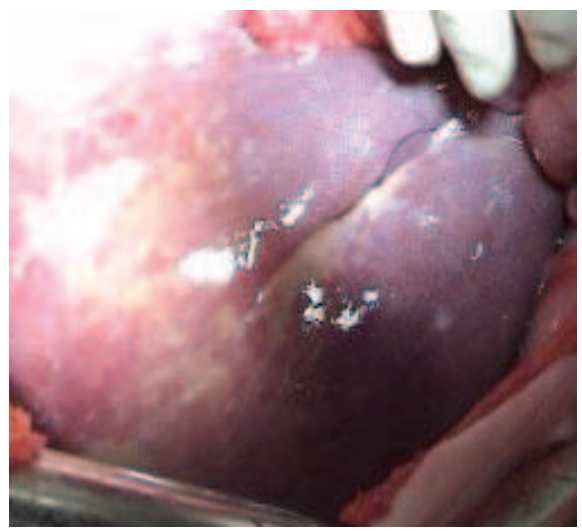

Fig. 13. The aspect of the graft at the moment of reperfusion

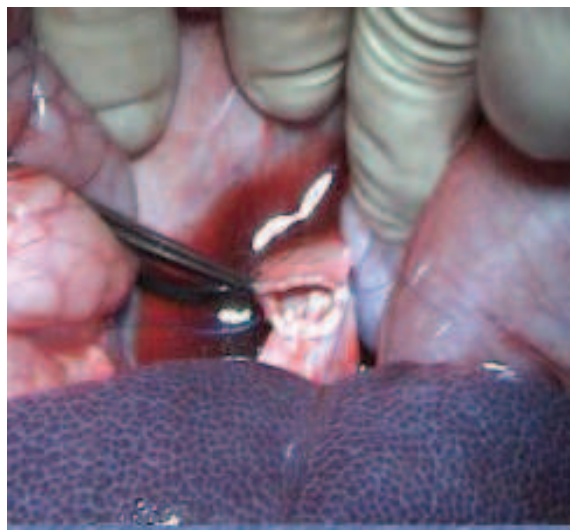

Fig. 14. The donor's infrahepatic inferior cava vein is anastomosed end-to-end to the recipient's homolog vein first performing a continuous suture on the posterior wall

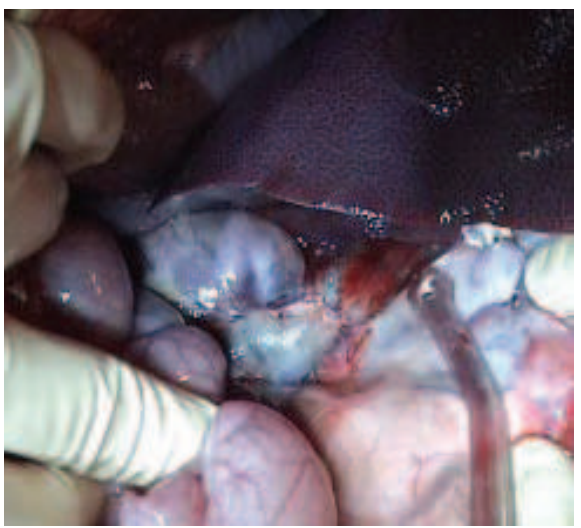

Fig. 15. The infrahepatic inferior cava vein anastomosis is checked for bleeding sites 
After revascularization of the liver, the role of the anesthesiologist is crucial in dealing with reperfusion syndrome. For this it is necessary to monitor the pulmonary pressure, central venous pressure and cardiac index using Swan-Ganz catheter fixed on the right cephalic vein. (Filliponi et al., 1998) No vasoconstrictive drugs are recommended to correct postreperfusion arterial hypotension. Only fluids to correct volemia should be used instead.

During hypothermia of a liver to be transplanted, a large quantity of $\mathrm{K}+$ and $\mathrm{H}+$ accumulates, which may cause cardiac arrhythmia at revascularization. To preclude the reperfusion syndrome, the metabolites and potassium ions entering into systemic circulation can be removed from the graft by liver flushing. Before doing the portal revascularization of the donor livers, a washout via both the portal vein and hepatic artery can be performed with saline serum (Arias et al., 1987) or polygeline solution (Haemaccel) (Arias et al., 1990). The liver can also be washed only via portal vein with $500 \mathrm{ml}$ warm $\left(37^{\circ} \mathrm{C}\right)$ lactated Ringer's solution at room temperature before finishing the vein anastomosis. Then approximately 250-500 $\mathrm{ml}$ of recipient's blood are allowed to drain through the intrahepatic inferior vena cava after finishing the portal anastomosis. (Sirbu Boeti et al., 2008) During all the warm perfusion time the suprahepatic cava is maintained clamped and the washing fluids (lactated Ringer's solution and blood) are aspirated through the infrahepatic inferior caval vein stump. This fact also contributes to the controlled heating of the liver before including it into the circulatory system. The procedure of liver warm reperfusion was inspired by previous studies made on rats. (Takei \& et al., 1991; Xu et al., 1992)

When the liver transplantation is performed without by-pass, the warm flush with lactated Ringer's solution is performed before rather than after vascular clamping in the recipient. Flushing the graft with the vena cava and portal vein clamped add several more minutes of splanhnic venous stasis, leading to an even greater release of cytokines and inflammatory mediators upon the restoration of flow. (Fondevila et al., 2010) An extracorporeal circulation (ECC) equipped with a polyacrylonitrile dialyzer (PAN) between the previously anastomized inferior vena cava (IVC) below the liver and the jugular vein is a solution used to entrap and thus preclude the $\mathrm{K}+$ to enter the systemic circulation. (Marino \& De Luca, 1985) Some authors consider that metabolic acidosis can be avoided by administration of sodium bicarbonate before declamping and corrections of alterations in serum electrolytes. (Torres et al., 2008)

Immediately after declamping of suprahepatic inferior vena cava and portal vein with subsequent revascularization of the liver, the reperfusion syndrome must be readily recognized and controlled. Swine hemodynamic status during anhepatic phase was analyzed by different authors. (Fondevila et al. 2010; Heuer et al., 2010; Torres et al., 2008)

In the unfortunate case of intraoperative sudden death of the recipient the operation should be continued with the aim of improvement of surgical techniques.

The hepatic artery of the pig has a 1.5-2.5 mm caliber which makes its suturing difficult. Hepatic artery can be reconstructed using microsurgical techniques under a magnification of 6.5 X. The donor's artery is adequately tailored to avoid tension or kinking. Vascular edges are obliquely sectioned or "fish mouth" shaped, for obtaining a larger caliber and protecting the arterial anastomosis from thrombosis and stenosis. The arterial stumps should be 
washed with Papaverine solution (1 vial in $15 \mathrm{ml}$ of warm saline). A minimum resection of the adventitia is intended, removing only the fragments hanging outside the edges of the vessel. The end-to-end microsurgical anastomosis of the proper hepatic arteries of the donor and recipient can be executed according to $0-180^{\circ}$ technique with separate $8-0$ or $9-0$ monofilament stitches. (Sirbu Boeti et al., 2008) At the end of the anastomosis there is no need for the patency test. The arterial reconstruction can also be made using an aortic graft sutured end-to-side to the infrarenal aorta (Figure 16). (Oike et al., 2001; Oldhafer et al., 1993) The cuff technique can also be used for arterial reconstruction. (Monden et al., 1982) A technique of orthotopic liver transplantation in the pig was described in which the main feature is the accomplishment of vascular anastomoses by the use of the Vogelfanger NRC vascular suturing instrument. The advantage of this instrument was the rapid accomplishment of safe leak-proof anastomoses. (Barron et al. 1975)
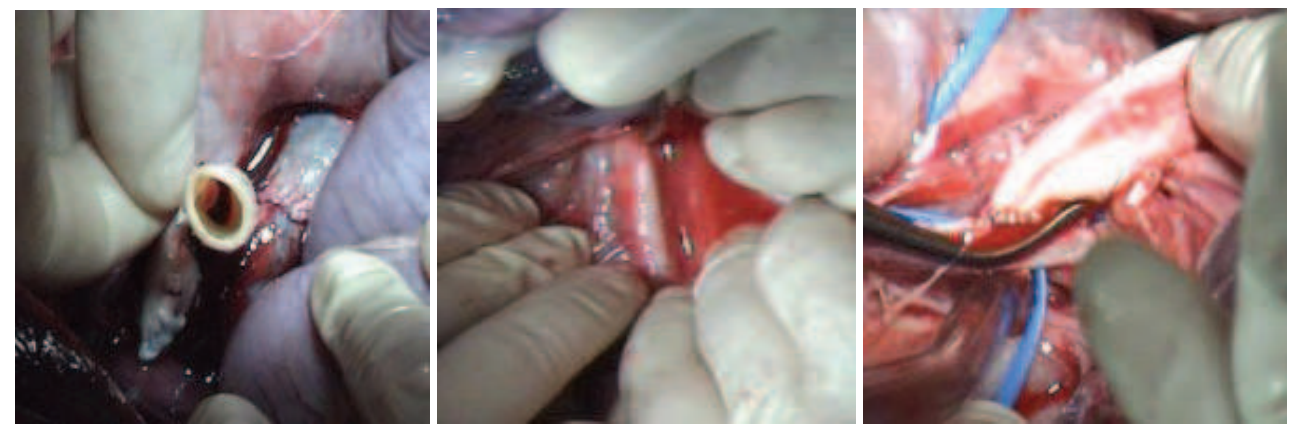

Fig. 16. Arterial reconstruction using an aortic graft. A. Back bleeding in the aortic graft.

B. Identification of infrarenal abdominal aorta. C. End-to-side arterial anastomosis between donor's aortic graft and recipient's infrarenal aorta

Regarding the biliary reconstruction, some authors suggest choledocho-choledochostomy to be the most appropriate. The common biliary duct is wide enough to permit a safe anastomosis with 6-0 polydioxanone (PDS®, Ethicon, Inc.) suture. If a silastic tube is introduced in the open ends of the donor's and recipient's common bile duct, no sutures are necessary because the apposition is accomplished by securing the silastic tube with two ligatures which are then tied to one another. (Fondevila et al., 2010) Choledochojejunostomy with a Roux-Y-loop, choledocho-duodenostomy, cholecysto-jejunostomy with a Roux-Y loop (Oike et al., 2001) and cholecysto-duodenostomy can also be chosen for the biliary reconstruction. If the donor's gallbladder is preserved, a cholecysto-gastrostomy is very facile to be performed (Figure 17). However choledocho-choledochostomy is preferred to the biliary-duodenal anastomosis to avoid postoperative cholangitis and also to the biliary-jejunal anastomosis to avoid the danger of intestinal obstruction, which is highly common in pigs. (Lempinen et al., 1971) External biliary drainage is another alternative. (Oldhafer et al., 1993)

When an end-to-end anastomosis of the bile duct is performed for orthotopic liver allotransplantation, $70 \%$ of the subjects develop jaundice at the end of the first week after transplantation. (Battersby et al., 1975) However the jaundice is generally a result of transient rejection and usually resolves spontaneously without immunosuppression. (Battersby et al., 1975) 


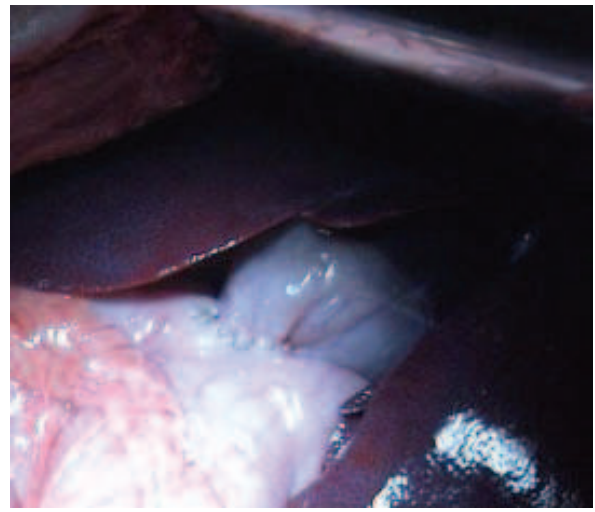

Fig. 17. Cholecysto-gastrostomy performed with continuous 6-0 PDS suture

\section{Conclusions}

The orthotopic liver transplantation models on swine are straightforward and reproducible and offer surgeons and researchers the opportunity to perform and study liver transplantation in conditions similar to clinical practice.

\section{References}

Ambiru, S.; Uryuhara, K.; Talpe, S.; Dehoux, J.P.; Jacobbi, L.; Murphy, C.J.; McAnulty, J.F. \& Gianello, P. Improved survival of orthotopic liver allograft in swine by addition of trophic factors to University of Wisconsin solution. Transplantation, Vol.77, No.2, (January 2004), pp:302-319. ISSN 0041-1337

Arias, J.; Aller, M.A.; Fernandez-Cordero, X.; Estebanez, E.; Jimenez, G.; Enterria, F.G; Brandau, D. \& Duran, H. Portal and arterial washout after hypothermic preservation of the pig liver: prevention of hyperkalaemia after revascularization. Int Surg, Vol.72, No.3, (July 1987), pp:134-140. ISSN 0020-8868

Arias, J.; Aller, M.A.; Lorente, L.; Rodriguez, J.C.; Fernandez, X.; Brandau, D.\& Duran, H. Washout of the pig liver with Haemaccel after hypothermic preservation. Int Surg, Vol.75, No.2, (April 1990), pp:78-83. ISSN 0020-8868

Audet, M.; Alexandre, E.; Mustun, A.; David, P.; Chenard-Neu, M.P.; Tiollier, J.; Jaeck, D.; Cinqualbre, J.; Wolf, P.\& Boudjema, K. Comparative evaluation of Celsior solution versus Viaspan in a pig liver transplantation model. Transplantation, Vol.71, No.12, (June 2001), pp:1731-1735. ISSN 0041-1337

Barbier, P.A.; Luder, P.J.; Wagner, H.E.; Barbier, A. \& Mettler, D. Orthotopic liver transplantation in pigs without cold perfusion of the donor liver. Evaluation by quantitative liver function tests. Eur Surg Res, Vol.18, No.5, (May 1986), pp:293-301. ISSN 1421-9921

Barron, P.T.; Vogelfanger, I.J. \& Waddell, W.G. Orthotopic liver transplantation utilizing a vascular stapling instrument. Br J Surg, Vol.62, No.6, (June 1997), pp:438-440. ISSN $1365-2168$ 
Battersby, C.; Egerton, W.S.; Balderson, G.; Kerr, J.F. \& Burnett, W. Early jaundice after pig liver transplantation. Aust N Z J Surg, Vol.45, No.2, (May 1975), pp:209-213. ISSN 1445-2197

Battersby, C.; Hickman, R.; Saunders, S.J. \& Terblanche, J. Liver function in the pig. The effects of 30 minutes' normothermic ischaemia. Br J Surg, Vol.61, No.1, (January 1974), pp:27-32. ISSN 1365-2168

Calne, R.Y.; Yoffa, D.E.; White, H.J. \& Maginn, R.R. A technique of orthotopic liver translantation in the pig. Br J Surg, Vol.55, No.3, (March 1968), pp:203-206. ISSN 1365-2168

Cannon, J.A. Organs (communication). Transplant Bull, (1956), 3:7.

Cordier, G.; Garnier, H.; Clot, J.P.; Camplez, P.; Gorin, J.P.; Clot, P.; Rassinier, J.P.; Nizza, M. \& Levy, R. [Orthotopic liver graft in pigs. 1st results]. Mem Acad Chir (Paris), Vol.92, No.27, (November 1966), pp:799-807. ISSN 1634-0647

Falcini, F.; Martini, E.; Marsili, M.; Benassai, C.; Fabbri, L.P.; Tanini, R.; Linden, M.; Simoncini, R.; Filipponi, F. \& Cataliotti, L. Veno-venous bypass in experimental liver transplantation: portal-jugular versus caval-portal-jugular. G Chir 1990; 11:206-210. ISSN 0391-9005

Filipponi, F.; Falcini, F.; Marsili, M. \& Boncinelli, S. A new perfusion system for the treatment of isolated pig liver damaged by warm ischemia. Int J Artif Organs, Vol.13, No.4, (April 1990), pp:257-258. ISSN 0391-3988

Filipponi, F.; Leoncini, G.; Campatelli, A.; Bagnolesi, A.; Perri, G.; Romagnoli, P. \& Mosca, F. Segmental organization of the pig liver: anatomical basis of controlled partition for experimental grafting. Eur Surg Res 1995; Vol.27, No.3, (March 1995), pp:151-157. ISSN 1421-9921

Filipponi, F.; Oleggini, M.; Romagnoli, P.; Fossati, N.; Pardini, P. \& Mosca, F. Exclusively aortic cold flushing for liver procurement from hemodynamically stable donors. An experimental study in the pig. G Chir, Vol.17, No.1-2, (January 1996), pp:59-63.

Filipponi, F.; Trivella, M.G.; Oleggini, M.; Pardini, P.; Meacci, L.; Bellissima, G.; Solari, R.; Porcelli, F.; Lucchetti, A.L.; Pardini, E. \& Mosca, F. Surgical research in orthotopic liver transplantation: experiences in the pig model. G Chir, Vol.17, No.4, (April 1996), pp:201-209.

Filipponi, F.; Boggi, U.; Della Capanna, S.; Carmellini, M.; Meacci, L. \& Mosca, F. 1998. Surgical research on orthotopic liver transplantation: Tuscany experience in the pig model. In: Liver transplantation: from laboratory to clinic, Filiponi F, pp:12-71, Guido Gnocchi Editore (Ed.), ISBN 9781928649045, Napoli

Foley, D.P.; Vittimberga, F.J.; Quarfordt, S.H.; Donohue, S.E.; Traylor, A.N.; MacPhee, J.; McLaughlin, T.; Ricciardi, R.; Callery, M.P. \& Meyers, W.C. Biliary secretion of extracorporeal porcine livers with single and dual vessel perfusion. Transplantation, Vol.68, No.3, (August 1999), pp:362-368. ISSN 0041-1337

Fondevila, C.F.; Hessheimer, A.J.; Flores, E.; Vendrell, M.; Munos, J.; Escobar, B.; Calatayud, D.; Taura, P.; Fuster J. \& Garcia-Valdecasas J.C. Step-by-step guide for a simplified model of porcine orthotopic liver transplant. J Surg Res, Vol.167, No.1, (May 2011), pp: e39-45. ISSN 0022-4804

Garnier, H.; Clot, J.P.; Bertrand, M.; Camplez, P.; Kunlin, A.; Gorin, J.P.; Le Goaziou, F.; Levy, R. \& Cordier, G. [Liver transplantation in the pig: surgical approach]. $C R$ Acad Sci Hebd Seances Acad Sci D, Vol.260, No.21, (May 1965), pp:5621-5623. ISSN 0762-0969 
Heuer, M.; Reinhardt, R.; Kneiseler, G.; Wurzinger, P.; Zou, X.; Hua, F.; Jian, F.; Paul, A. \& Kaiser, G.M. Liver transplantation in swine without venovenous bypass. Eur Surg Res, Vol.45, No.1, (August 2010), pp:20-25. ISSN 1421-9921

Kaiser, G.M.; Heuer, M.M.; Fruhauf, N.R.; Kuhne, C.A. \& Broelsch, C.E. General handling and anesthesia for experimental surgery in pigs. J Surg Res, Vol.130, No.1, (January 2006), pp:73-79. ISSN 0022-4804

Kaupp, H.A. \& Starzl, T.E. The use of an external bypass during experimental total hepatectomy. Surgery, Vol.48, (August 1960), pp:330-331. ISSN 0039-6060

Marino, I.R. \& De Luca, G. Orthotopic liver transplantation in pigs. An evaluation of different methods of avoiding the revascularization syndrome. Transplantation, Vol.40, No.5, (November 1985), pp:494-498. ISSN 0041-1337

Mieny, C.J.; Moore, A.R.; Homatas, J. \& Eiseman, B. Homotransplantation of the liver in pigs. S Afr J Surg, Vol.5, No.3, (July 1967), pp:109-114. ISSN 0038-2361

Monden, M.; Barters, R.H. \& Fortner, J.G. A simple method of orthotopic liver transplantation in dogs. Ann Surg, Vol.195, No.1, (January 1982), pp:110-113. ISSN 0003-4932

Moore, F.D.; Smith, L.L.; Burnap, T.K.; Dallenbach, F.D.; Dammin, G.J.; Gruber, U.F.; Shoemaker, W.C.; Steenburg, R.W.; Ball, M.R. \& Belko, J.S. One-stage homotransplantation of the liver following total hepatectomy in dogs. Transplant Bull, Vol.6, No.1, (January 1959), pp:103-107 ISSN 0564-1217

Oike, F.; Uryuhara, K.; Otsuka, M.; Dehoux, J.P.; Otte, J.B.; Lerut, J. \& Gianello, P. Simplified technique of orthotopic liver transplantation in pigs. Transplantation, Vol.71, No.2, (January 2001), pp:328-331. ISSN 0041-1337

Oldhafer, K.J.; Hauss, J.; Gubernatis, G.; Pichlmayr, R. \& Spiegel, H.U. Liver transplantation in pigs: a model for studying reperfusion injury. J Invest Surg, Vol.6, No.5, (September 1993), pp:439-450. ISSN 0894-1939

Sirbu Boeti, M.P.; Romanescu, D.; Gangone, E.; Grigorie, R.; Barbulescu, M.; Elshorbagy, A.; Jemna, C.; Efrimescu, C.; Ionescu, S.; Clinciu, P.; Badea, R. \& Popescu, I. Swine model of orthotopic liver transplantation. Annals of Fundeni Hospital, Vol.13, No.1, (January 2008), pp:3-11. ISSN 1224-3450

Takei, Y.; Marzi, I.; Kauffman, F.C. \& Lemasters, J.J. Increase in survival of liver grafts after rinsing with warm Ringer's solution due to improvement of hepatic microcirculation. Transplantation, Vol.52, No.2, (August 1991), pp:225-230. ISSN 0041-1337

Torres, O.J.; Pantoja, P.B.; Barbosa, E.S.; Barros, C.A; Servin, E.T. \& Servin, S.C. Hemodynamic alterations during orthotopic liver experimental transplantation in pigs. Acta Cir Bras, Vol.23, No.2, (March 2008), pp:135-139. ISSN 1678-2674

Xu, H.S.; Wang, D.J.; Pace, R.C. \& Jones, R.S. Beneficial effects of prewarming the donor liver for rat liver transplantation. Am J Surg. Vol.163, No.1, (January 1992), pp:164168. ISSN 0002-9610

Welch, C.S. \& Welch, C.S. A note of transplantation of the whole liver in dogs. Transplant Bull, Vol.2, (1955), pp:54. ISSN 0564-1217 


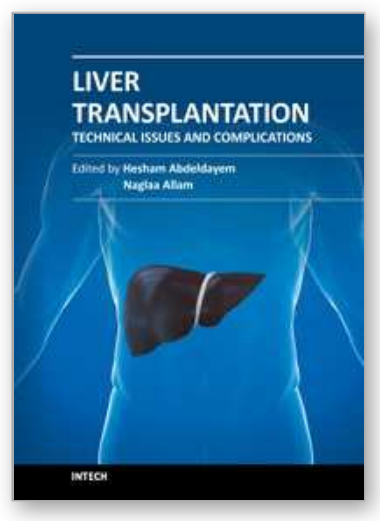

\author{
Liver Transplantation - Technical Issues and Complications \\ Edited by Prof. Hesham Abdeldayem
}

ISBN 978-953-51-0015-7

Hard cover, 454 pages

Publisher InTech

Published online 10, February, 2012

Published in print edition February, 2012

This book covers a wide spectrum of topics including, but not limited to, the technical issues in living and deceased donor liver transplant procedures, cell and experimental liver transplantation, and the complications of liver transplantation. Some of the very important topics, such as the arterial reconstruction in living donor liver transplantation, biliary complications, and the post-transplant-lymphoprolifrative disorders (PTLD), have been covered in more than one chapter.

\title{
How to reference
}

In order to correctly reference this scholarly work, feel free to copy and paste the following:

Mirela Patricia Sîrbu Boeți, Sadiq Shoaib, Alaa Elshorbagy, Cătălin lulian Efrimescu and Irinel Popescu (2012). Experimental Liver Transplantation, Liver Transplantation - Technical Issues and Complications, Prof. Hesham Abdeldayem (Ed.), ISBN: 978-953-51-0015-7, InTech, Available from: http://www.intechopen.com/books/livertransplantation-technical-issues-and-complications/experimental-liver-transplantation

\section{INTECH}

open science | open minds

\section{InTech Europe}

University Campus STeP Ri

Slavka Krautzeka 83/A

51000 Rijeka, Croatia

Phone: +385 (51) 770447

Fax: +385 (51) 686166

www.intechopen.com

\section{InTech China}

Unit 405, Office Block, Hotel Equatorial Shanghai

No.65, Yan An Road (West), Shanghai, 200040, China

中国上海市延安西路65号上海国际贵都大饭店办公楼 405 单元

Phone: +86-21-62489820

Fax: $+86-21-62489821$ 
(C) 2012 The Author(s). Licensee IntechOpen. This is an open access article distributed under the terms of the Creative Commons Attribution 3.0 License, which permits unrestricted use, distribution, and reproduction in any medium, provided the original work is properly cited. 